\title{
Recombinant human soluble thrombomodulin in patients with sepsis- associated coagulopathy (SCARLET): an updated meta-analysis
}

\author{
Kazuma Yamakawa ${ }^{1 *}$, Jerrold H. Levy ${ }^{2}$ and Toshiaki lba ${ }^{3}$
}

Letter to the editor

The reported trial of recombinant human soluble thrombomodulin (rTM) in sepsis failed to show a 28-day all-cause mortality reduction [1]. Although the primary efficacy results did not support the administration of rTM, we found a positive signal in a post hoc analysis in the SCARLET trial. We also are concerned about the eligibility of patient selection possibly caused by a protocol amendment that lengthened the allowable time period from first qualifying INR until dosing as noted in the JAMA editorial [2]. In this trial, approximately $22 \%$ of subjects in the full analysis set (182/816 patients) did not fulfill the protocol-specified coagulopathy criteria (INR > 1.4 and platelet count $>30 \times 10^{9} / \mathrm{L}$ ) when the first dose of the study drug was administered. This population was thought to have a lower grade of coagulation disorder and/or lower disease severity. We have previously shown the importance of selecting a target population for anticoagulant therapy in sepsis that should be based on two critical components that include a "coagulation disorder" and "high disease severity" [3]. The inadequate population of $22 \%$ reported in JAMA may attenuate the power to detect the effectiveness of the intervention [1].

Recently, we reported the latest systematic review and meta-analysis [4] of recombinant thrombomodulin for sepsis including SCARLET trial results that were made public in August 2018. The data of five trials enrolling 1762 patients showed that the pooled estimate on mortality of recombinant thrombomodulin use was not statistically significant (risk ratio, $0.87 ; 95 \%$ confidence interval, $\left.0.74-1.03 ; P=0.10 ; I^{2}=0 \%\right)$. A significant limitation of our meta-analysis was the lack of full results from the SCARLET trial. We therefore performed reanalyses by replacing the SCARLET results with a subgroup analysis of the proportion who still met the coagulopathy criteria at dosing. Consequently, mortality risk was reduced by the administration of recombinant thrombomodulin (risk ratio, 0.82; 95\% confidence interval, $0.69-0.98 ; P=0.03 ; I^{2}=0 \%$ ) (Fig. 1 ).

Importantly, as a limitation mentioned by Vincent et al., post hoc analyses used in this re-analyzed metaanalysis were not planned a priori and need to be interpreted with caution. To properly implement precision medicine, a strategy of selecting the optimal target of an individual intervention is essential [5]. SCARLET is the first trial intended to examine the effects of anticoagulants in coagulopathic patients. We suggest that further trials of recombinant thrombomodulin should be performed that focus on the strictly eligible population that can potentially benefit from this therapy.

\footnotetext{
*Correspondence: k.yamakawa0911@gmail.com

${ }^{1}$ Division of Trauma and Surgical Critical Care, Osaka General Medical Center,

3-1-56 Bandai-Higashi, Sumiyoshi, Osaka 558-8558, Japan

Full list of author information is available at the end of the article
} 


\begin{tabular}{|c|c|c|c|c|c|c|c|c|c|c|c|}
\hline Study or Subgroup & $\begin{array}{r}\text { rTM } \\
\text { Events }\end{array}$ & Total & $\begin{array}{l}\text { Contro } \\
\text { Events }\end{array}$ & $\begin{array}{l}\text { ol } \\
\text { Total }\end{array}$ & Weight & $\begin{array}{c}\text { Risk Ratio } \\
\text { M-H, Random, } 95 \% \mathrm{Cl}\end{array}$ & Year & \multicolumn{4}{|c|}{$\begin{array}{c}\quad \text { Risk Ratio } \\
\mathrm{M}-\mathrm{H}, \text { Random, } 95 \% \mathrm{Cl}\end{array}$} \\
\hline Aikawa 2011 & 9 & 42 & 12 & 38 & $5.5 \%$ & $0.68[0.32,1.43]$ & 2011 & & \begin{tabular}{l|l}
$\cdot$ \\
\end{tabular} & 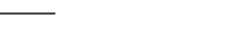 & \\
\hline Ushizawa 2012 & 6 & 22 & 10 & 27 & $4.3 \%$ & $0.74[0.32,1.71]$ & 2012 & & & & \\
\hline Vincent 2013 & 66 & 370 & 80 & 371 & $35.5 \%$ & $0.83[0.62,1.11]$ & 2013 & & 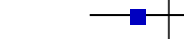 & - & \\
\hline Hagiwara 2016 & 8 & 47 & 7 & 45 & $3.5 \%$ & $1.09[0.43,2.77]$ & 2016 & & & & \\
\hline SCARLET trial 2019 & 82 & 307 & 105 & 327 & $51.3 \%$ & $0.83[0.65,1.06]$ & 2019 & & - & & \\
\hline Total $(95 \% \mathrm{Cl})$ & & 788 & & 808 & $100.0 \%$ & $0.82[0.69,0.98]$ & & & & & \\
\hline Total events & 171 & & 214 & & & & & & & & \\
\hline $\begin{array}{l}\text { Heterogeneity: } \mathrm{Tau}^{2}= \\
\text { Test for overall effect: }\end{array}$ & $\begin{array}{l}0.00 ; \mathrm{Chi}^{2} \\
\mathrm{Z}=2.17(\mathrm{~F}\end{array}$ & $\begin{array}{l}2=0.70 \\
P=0.03\end{array}$ & $\begin{array}{l}\text {, df }=4(P \\
3)\end{array}$ & $=0.95$ & $; I^{2}=0 \%$ & & & 0.2 & $\begin{array}{cc}0.5 & 1 \\
\text { Favours rTM }\end{array}$ & $\begin{array}{c}2 \\
\text { Favours Control }\end{array}$ & 5 \\
\hline
\end{tabular}

\section{Abbreviation}

rTM: Recombinant human soluble thrombomodulin

\section{Acknowledgements}

Not applicable.

\section{Authors' contributions}

$\mathrm{KY}, \mathrm{JHL}$, and $\mathrm{TI}$ were responsible for the conception of the letter. All authors drafted the manuscript. All authors read and approved the final manuscript.

\section{Funding}

This research did not receive any funding.

\section{Availability of data and materials}

Not applicable.

\section{Ethics approval and consent to participate}

Not applicable.

\section{Consent for publication}

Not applicable.

\section{Competing interests}

TI has participated in advisory boards of Asahi Kasei Pharmaceuticals. The other authors declare that they have no competing interests.

\section{Author details}

${ }^{1}$ Division of Trauma and Surgical Critical Care, Osaka General Medical Center, 3-1-56 Bandai-Higashi, Sumiyoshi, Osaka 558-8558, Japan. ²Department of Anesthesiology, Critical Care, and Surgery, Duke University School of Medicine, Durham, NC, USA. ${ }^{3}$ Department of Emergency and Disaster Medicine, Juntendo University Graduate School of Medicine, Tokyo, Japan.

Received: 17 August 2019 Accepted: 27 August 2019

Published online: 05 September 2019

\section{References}

1. Vincent JL, Francois B, Zabolotskikh I, Daga MK, Lascarrou JB, Kirov MY, et al. Effect of a recombinant human soluble thrombomodulin on mortality in patients with sepsis-associated coagulopathy. JAMA. 2019;321(20):1993-2002.

2. van der Poll T. Recombinant human soluble thrombomodulin in patients with sepsis-associated coagulopathy: another negative sepsis trial? JAMA. 2019;321(20):1978-80.

3. Yamakawa K, Umemura Y, Hayakawa M, et al. Benefit profile of anticoagulant therapy in sepsis: a nationwide multicentre registry in Japan. Crit Care. 2016;20(1):229

4. Yamakawa K, Murao S, Aihara M. Recombinant human soluble thrombomodulin in sepsis-induced coagulopathy: an updated systematic review and meta-analysis. Thromb Haemost. 2019;119(1):56-65.

5. Vincent $\mathrm{J}$. The coming era of precision medicine for intensive care. Crit Care. 2017;21(Suppl 3):314.

\section{Publisher's Note}

Springer Nature remains neutral with regard to jurisdictional claims in published maps and institutional affiliations. 